\title{
BMJ Open Clinical features and prognosis of patients with acute non-specific chest pain in emergency and cardiology departments after the introduction of high-sensitivity troponins: a prospective cohort study
}

Nivethitha llangkovan, ${ }^{1}$ Hans Mickley, ${ }^{2}$ Axel Diederichsen, ${ }^{2}$ Annmarie Lassen, ${ }^{3}$ Thomas L Sørensen, ${ }^{4}$ Hussam Mahmoud Sheta, ${ }^{5}$ Peter B Stæhr, ${ }^{1}$ Christian Backer Mogensen ${ }^{6}$

To cite: llangkovan $\mathrm{N}$ Mickley H, Diederichsen A, et al. Clinical features and prognosis of patients with acute non-specific chest pain in emergency and cardiology departments after the introduction of high-sensitivity troponins: a prospective cohort study. BMJ Open 2017;7:e018636. doi:10.1136/ bmjopen-2017-018636

- Prepublication history for this paper is available online. To view these files, please visit the journal online (http://dx.doi. org/10.1136/bmjopen-2017018636).

Received 11 July 2017

Revised 15 November 2017 Accepted 21 November 2017

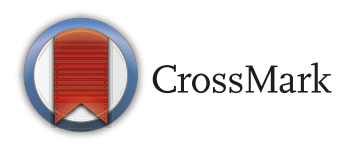

For numbered affiliations see end of article.

Correspondence to Dr Nivethitha llangkovan; nilangkovan@gmail.com

\section{ABSTRACT}

Objectives To determine the incidence of clinical, cardiac-related endpoints and mortality among patients presenting to an emergency or cardiology department with non-specific chest pain (NSCP), and who receive testing with a high-sensitivity troponin. A second objective was to identify risk factors for the above-noted endpoints during 12 months of follow-up.

Design A prospective multicentre study.

Setting Emergency and cardiology departments in Southern Denmark.

Subjects The study enrolled 1027 patients who were assessed for acute chest pain in an emergency or cardiology department, and in whom a myocardial infarction or another obvious reason for chest pain had been ruled out. Patients were enrolled from September 2014 to June 2015 and followed for 1 year.

Main outcome measures Clinical, cardiac-related endpoints (cardiac-related death, acute myocardial infarction, unstable angina and coronary revascularisation) and all-cause mortality.

Results Over a period of 1 year, cardiac-related endpoints were found in 19 patients (1.9\%): 0 patients experienced cardiac-related death, $2(0.2 \%)$ had myocardial infarction, $4(0.4 \%)$ had unstable angina pectoris and $17(1.7 \%)$ underwent coronary revascularisation. All-cause mortality was observed in seven patients $(0.7 \%)$. When compared with the general population, the standardised mortality ratio did not differ. The risk factors associated with the study endpoints included male gender, body mass index $>25 \mathrm{~kg} / \mathrm{m}^{2}$, previous known coronary artery disease, hypertension, hypercholesterolaemia, diabetes mellitus and the use of statins. A total of $73 \%$ of the endpoints occurred in males.

Conclusion The prognosis for patients with NSCP is favourable, with a 1-year mortality after discharge that is comparable with the background population. Few clinical endpoints took place during follow-up, and those that did were predominantly in males.

\section{Strengths and limitations of this study}

No patients were lost to follow-up.

- Multicentre study enrolling patients from six hospitals.

- Few events during follow-up.

- The cohort was relatively unselected.

- The clinical endpoints were based on physician assessment and not otherwise validated.

\section{INTRODUCTION}

Patients with acute chest pain or discomfort represent a large proportion of referrals to emergency and cardiology departments. Although fewer than $20 \%$ of these patients are diagnosed with an acute myocardial infarction (MI) ${ }^{1-4}$ the absence of one does not rule out possible underlying coronary artery disease $(\mathrm{CAD})$. CAD is associated with $20 \%$ of all deaths in Europe. ${ }^{5}$ Discharge diagnoses after an admission for acute chest pain include the clinical manifestations of CAD (unstable angina pectoris (UAP) or $\mathrm{MI}$ ), other cardiac-related diagnoses (aortic dissection or pulmonary embolus), noncardiac disorders (gastrointestinal, respiratory or musculoskeletal) and non-specific chest pain (NSCP). This latter group comprised patients who are discharged without a plausible explanation for their symptoms. While the former groups are well described in literature, ${ }^{67}$ patients with NSCP receive comparatively little attention, although they are not entirely ignored. Previous studies have noted that patients with NSCP have frequent contact with healthcare systems and high medication 
use. $^{8}$ Other studies have revealed that $0.6 \%-0.8 \%$ of patients with NSCP who are seen in emergency department (ED) have a major cardiac event within 30 days of discharge. $^{910}$

In this multicentre study, we examined patients who were discharged from an emergency or cardiology department with a diagnosis of NSCP after routine clinical care, including testing with a high-sensitivity troponin (hsTn). The principle objective was to describe the outcomes of patients with NSCP with respect to clinical, cardiac-related events and all-cause mortality during 1 year of follow-up. A second objective was to identify risk factors for predicting ischaemic cardiac events in the first year after discharge.

\section{METHODS}

\section{Design}

The study was structured as a prospective multicentre cohort study. Six hospitals in the Region of Southern Denmark participated: Aabenraa Hospital, Sonderborg Hospital, Odense University Hospital, Svendborg Hospital, Vejle Hospital and Kolding Hospital. The study enrolled consecutive patients admitted to emergency or cardiology departments with acute chest pain or discomfort. Patients received a routine physician evaluation that included testing with a hsTn assay.

\section{Study population}

The study included patients aged 30-70 years who were referred with chest pain to emergency or cardiology departments, and who had at least one hsTn measurement in the first 24 hours following admission. Patients were prospectively enrolled during a 9-month period from September 2014 to June 2015, and followed until June 2016 or for a minimum of 1 year, until emigration, or until death.

Patients were identified for study eligibility by searching daily through the central biochemical database, which stores laboratory results for patients in the Region of Southern Denmark. An hsTn T value $<14 \mathrm{ng} / \mathrm{L}$ or an hsTn I value $<25 \mathrm{ng} / \mathrm{L}$ was required for inclusion. The attending physician's discharge diagnosis was recorded, and patients were considered to have NSCP if any of the following international diagnosis code (International Classification of Diseases 10 (ICD-10) codes) were given: DR072 (precordial chest pains), DR073 (other chest pains), DZ034 (observation for MI) or DZ035 (observation for coronary disease). A structured phone interview was completed within 3 days of discharge.

Patients were excluded from the study if they were not contacted within 3 days of discharge (after three calls were made on different days and at different times), if they did not understand either Danish or English, if they were intoxicated, if they were pregnant, if they had an obvious cause for their chest pain or discomfort or if they had normal coronary angiography during the index admission. Additionally, patients were excluded from the study if they did not provide consent for follow-up or if medical records from their index admission were unavailable.

\section{Material and data}

A phone interview was conducted by the first author or by one of the two nurses who participated in the study. Patients received standardised questions pertaining to symptoms that they had at the time of index contact, as well as questions regarding their medical history and their risk factors for CVD. The study questionnaire was validated for interobserver validity, with a finding of $72 \%$ agreement between interviewers. Following the interview, patients were mailed a consent form requesting access to their health records, which contained clinical, laboratory and imaging results.

\section{Definitions}

Smoking was quantified in pack years, with one pack year defined by 20 cigarettes, per day, per year. Hypertension, hypercholesterolaemia and diabetes were self-reported conditions. Family history was considered positive if any first degree relative, regardless of age, had known CVD. Statins were identified using the Anatomical Therapeutic Chemical code C10AA.

The medical history was established using ICD-10 diagnoses from admissions that occurred in the 10 years preceding the index visit. Subsequently, these were grouped into clinical categories: prior CAD included the ICD-10 diagnoses for acute and chronic ischaemic heart disease; peripheral arterial disease (PAD) included the diagnostic codes for intermittent claudication and atherosclerotic disease; ischaemic cerebral disease included the codes for apoplexy and transitory cerebral ischaemia and supraventricular tachycardia included the codes for atrial fibrillation and atrial flutter.

Since comorbidity is a recognised confounding variable for CVD, Charlson comorbidity index scores were calculated for participants. ${ }^{1112}$ This was done using the primary discharge diagnosis from admissions that occurred in the 10 years prior to the index visit. The diagnosis specified by the attending physician at the time of admission(s) was the recorded primary discharge diagnosis; this was not validated by a chart review or other means.

Data on prescription medications were obtained using information accessed from the Odense Pharmacoepidemiologic Database. ${ }^{13}$ Patients were considered to have used a statin if they had filled a prescription for one in the 3 months before the index admission.

\section{Clinical outcomes}

The primary outcome was a composite endpoint of all-cause mortality and clinical cardiac-related endpoints. Patients were classified as having a clinical cardiac-related endpoint if any of the following occurred during the year of follow-up: cardiac death, acute MI, UAP, or coronary revascularisation.

The endpoints were identified using information collected from the National Patient Register ${ }^{14}$ and the 
Civil Registration System, ${ }^{15}$ which included diagnostic codes entered by attending physicians.

\section{HsTn assays}

The study used the hsTn assays hsTnI or hsTnT, both with a 99th percentile cut-off point. Odense University Hospital used hsTnI, which was analysed by Abbot Diagnostics Architect with an upper reference limit of $25 \mathrm{ng} / \mathrm{L}$. The $10 \%$ coefficient of variation (CV) was $5 \mathrm{ng} / \mathrm{L}$ and the MI decision limit was $\geq 25 \mathrm{ng} / \mathrm{L} .{ }^{16}$ All other participating hospitals used hsTnT, which was analysed by Roche Diagnostic Elecsys 2010, modular analytics E170, Cobas e411 and Cobas e601. The 99th percentile cut-off value was $14 \mathrm{ng} / \mathrm{L}$, the $10 \% \mathrm{CV} 13 \mathrm{ng} / \mathrm{L}$ and the MI decision limit was $\geq 14 \mathrm{ng} / \mathrm{L}^{17}$

\section{Sample size calculations}

With a sample of 1298 patients, the study had a power of $80 \%$ and a two-sided CI of $95 \%$ for identifying risk factors that occurred $20 \%$ more frequently in patients with the pre-specified outcomes of all-cause mortality and clinical, cardiac-related endpoints. We assumed that clinical outcomes would occur in $2 \%$ of patients who were unexposed to the risk factors of interest, and in $5 \%$ of patients who were exposed to the risk factors.

\section{Statistics}

Continuous variables were organised into categorical subgroups, with the exception of age, which was reported in medians with interquartile ranges. Receiver-operating characteristic curves were calculated for each variable to identify acceptable cut-off points. Categorical variables were reported in frequency and percentages, and the Pearson's $\chi^{2}$ test was used to make intergroup comparisons. Any unobtained laboratory data were analysed as missing data.

Patients were followed until the first clinical endpoint occurred. Unadjusted event data were shown as a failure plot. The prognostic effect of variables on the clinical endpoints was analysed by univariate cox regression. More variables were tested than reported, but all significant variables were reported, in addition to select, clinically relevant, non-significant variables. A $\mathrm{P}$ value $<0.05$ was considered significant.

From Statistics Denmark, we obtained population size and mortality among people aged 30-70years living in the Region of Southern Denmark in 2015. We used this information to calculate the expected mortality ratio for the study population. The observed mortality ratio in the NSCP study population was then compared with the expected mortality ratio, and adjusted for age and gender to estimate the standardised mortality ratio in the study sample compared with the general population. Data were analysed using STATA v.14.2 0 (Stata, College Station, Texas).

Written, informed consent to access records was sent to participants after their phone interviews and confirmed prior to accessing their records.
RESULTS

Among 1213 eligible patients, 1027 returned their consent forms and were included in the study. Figure 1 shows the flow chart for patient inclusion and exclusion. Patients who were eligible for study and completed the interview, but did not return their consent, are referred to as non-participants. A comparison between participants $(n=1027)$ and non-participants $(n=186)$ showed a significant difference in median age and gender: the median age for participants was 54 years (IQR: 47-62) versus 47 years (IQR: 39-56) for non-participants, $\mathrm{P}=0.001$; females comprised 568 (55\%) of participants and $90(48 \%)$ of non-participants, $\mathrm{P}=0.081$. Two patients left Denmark before the end of the follow-up period.

Baseline characteristics for the participants are shown in table 1. Patients with a clinical endpoint were significantly older with a median age of 61 (IQR: 47-62), were predominantly male $(73 \%)$, had a Charlson score $\geq 1$, used a statin and had more vascular comorbidity at baseline compared with patients who did not experience a clinical endpoint.

Table 2 lists study outcomes after 30 days and 1 year. At the 30-day follow-up, all-cause mortality was zero $(0 \%$, 95\% CI: $0 \%$ to $0.3 \%)$, two participants had an MI $(0.2 \%$, 95\% CI: $0 \%$ to $0.5 \%)$, none had UAP $(0 \%, 95 \%$ CI: $0 \%$ to $0.3 \%$ ) and four underwent coronary revascularisation $(0.4 \%, 95 \%$ CI: $0.01 \%$ to $0.8 \%)$. The 30-day composite endpoint of all-cause mortality and clinical, cardiac-related endpoints was experienced by five patients $(0.5 \%$, $95 \%$ CI: $0.1 \%$ to $0.9 \%$ ).

At the 1-year follow-up, a total of seven patients in the cohort had died $(0.7 \%, 95 \% \mathrm{CI}: 0.2 \%$ to $1.2 \%)$. Compared with the general population, the standardised mortality ratio was 1.2 (95\% CI: 0.5 to 2.4$)$. The number of patients with clinical, cardiac-related endpoints was 19 (1.9\%; $95 \%$ CI: $1.0 \%$ to $2.7 \%)$. During this study period, no cardiac-related death was observed ( $0 \%, 95 \%$ CI: $0 \%$ to $0.3 \%), 2$ patients $(0.2 \%, 95 \%$ CI: $0 \%$ to $0.5 \%)$ had an MI, 4 patients $(0.4 \%, 95 \%$ CI: $0.01 \%$ to $0.1 \%)$ experienced UAP and 17 patients (1.7\%; 95\% CI: $0.9 \%$ to $2.4 \%$ ) underwent coronary revascularisation. In total, 26 patients had 30 events, such that the composite endpoint of all-cause mortality and clinical, cardiac-related endpoints occurred in $26 / 1027$ patients $(2.5 \%, 95 \%$ CI $1.6 \%$ to $3.5 \%)$. A total of $19(73 \%)$ of these composite endpoints occurred in male patients. The difference became more distinct with time, as demonstrated in the accumulated endpoints plot (figure 2), and depicted over the total length of the study (1.4 years).

Table 3 shows the HR for risk factors and outcomes after 1 year, as well as the CI for all clinical events, cardiac-related events and all-cause mortality. Whereas a univariate analysis was performed, a multivariate analysis was omitted due to the lack of clinical events. Variables significantly associated with clinical events included gender, a body mass index (BMI) $>25 \mathrm{~kg} / \mathrm{m}^{2}$, a Charlson score $>1$, pre-existing $\mathrm{CAD}$, combined ischaemic comorbidity (a 
Patients presenting to an ED or CD during the study period, who had a troponin measurement and were between the ages of 30-70 ( $n=4289)$.

Not assessed for study eligibility $(n=1857)$

hsTn $\mathrm{T} \geq=14 \mathrm{ng} / \mathrm{mL}$

hsTn I $\geq 25 \mathrm{ng} / \mathrm{mL}$

Discharged $\geq 3$ days from index admission

Patients with normal troponin $(n=2423)$
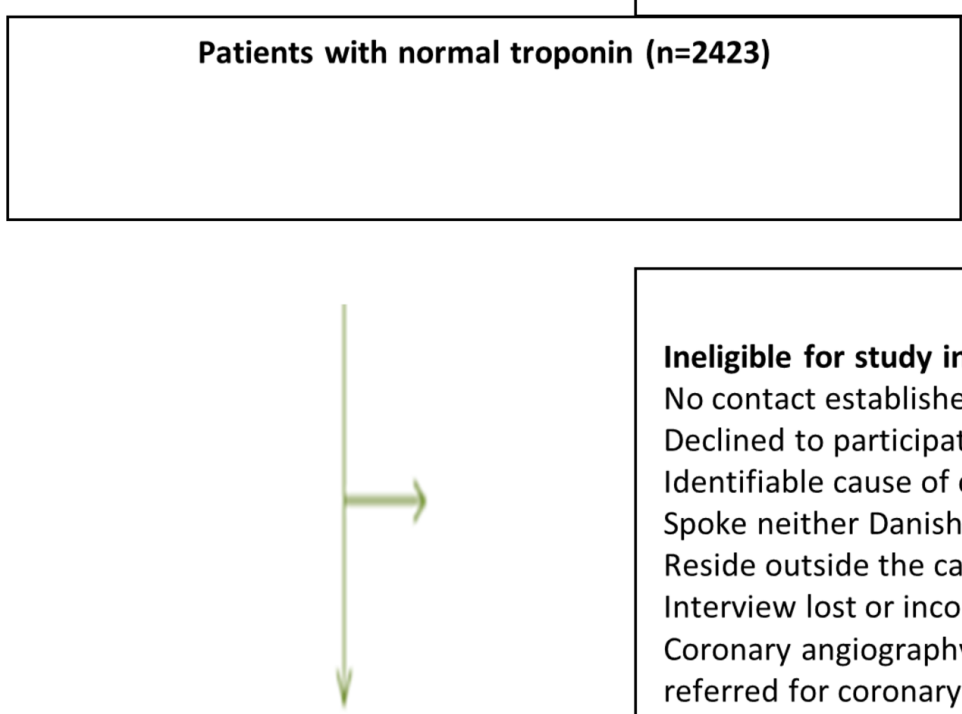

Ineligible for study inclusion (1210)

No contact established

Declined to participate

Identifiable cause of chest pain

Spoke neither Danish nor English

Reside outside the catchment area

Interview lost or incomplete

Coronary angiography during index admission or

referred for coronary angiography in a decision related to the

index admission

Chart information not located

Completed the interview

Eligible( $n=1213)$

Eligible, but not recruited $(n=186)$

Did not return consent

Figure 1 Flow chart for inclusion of study patients. CD, cardiology department; ED, emergency department; hsTn, highsensitivity troponin.

composite value that included CAD, ischaemic cerebral disease and PAD), hypertension, hypercholesterolaemia, diabetes and the use of statins. Of note, cholesterol laboratory values could not be obtained for $15 \%$ of study participants.

\section{DISCUSSION}

Prognosis for patients with NSCP

Patients with NSCP attract relatively little research attention. However, in this cohort study of 4289 patients, patients with NSCP represented nearly $25 \%$ of all patients 
Table 1 Descriptive baseline characteristics

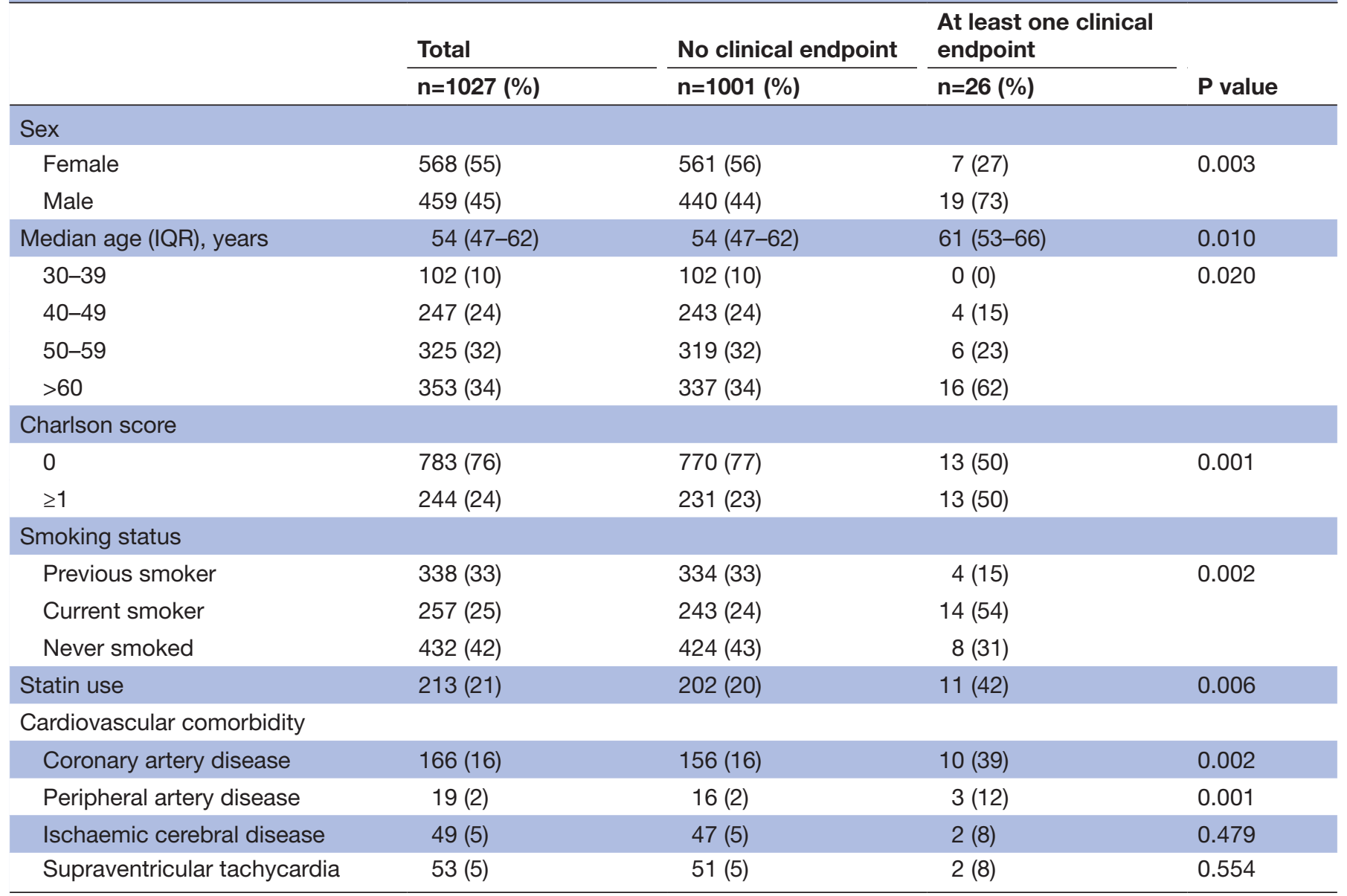

$P$ values are for $\chi^{2}$ test between patients with and without a clinical endpoint.

presenting to emergency or cardiology departments with chest pain or discomfort; they thus deserve additional focus.

This study found that patients with NSCP have a 1-year all-cause mortality of $0.7 \%$ and a risk of a clinical, cardiac-related endpoint of $1.9 \%$. In 2015, mortality for the general population, when adjusted for age and gender, was 1.2 (CI: 0.5 to 2.4$).{ }^{18}$ There was no significant mortality difference between the patients with NSCP enrolled in

Table 2 Endpoints at the 30-day and 1-year follow-up

\begin{tabular}{|c|c|c|c|c|}
\hline & \multicolumn{2}{|r|}{30 days } & \multicolumn{2}{|r|}{1 year } \\
\hline & $n=5$ & $\%$ & $\mathrm{n}=26$ & $\%$ \\
\hline Death & 0 & $0(0.0-0.3)$ & 7 & $0.7(0.2-1.2)$ \\
\hline $\begin{array}{l}\text { Cardiac-related } \\
\text { death }\end{array}$ & 0 & $0(0.0-0.3)$ & 0 & $0.0(0.0-0.3)$ \\
\hline $\begin{array}{l}\text { Myocardial } \\
\text { infarction }\end{array}$ & 2 & $0.2(0.0-0.5)$ & 2 & $0.2(0.0-0.5)$ \\
\hline $\begin{array}{l}\text { Unstable angina } \\
\text { pectoris }\end{array}$ & 0 & $0(0.0-0.3)$ & 4 & $0.4(0.0-0.8)$ \\
\hline Revascularisation & 4 & $0.4(0.1-0.8)$ & 17 & $1.7(0.9-2.4)$ \\
\hline $\begin{array}{l}\text { Composite } \\
\text { endpoint }\end{array}$ & 5 & $0.5(0.1-0.9)$ & 26 & $2.5(1.6-3.5)$ \\
\hline
\end{tabular}

this study and the general population; this confirms the favourable prognosis for patients with NSCP discharged from emergency or cardiology departments.

The results of our study are supported by two other studies that examined patients with NSCP. ${ }^{9} 10$ The first study showed that 30 days after ED discharge, $0.5 \%$ of patients with NSCP had an MI, $0.3 \%$ experienced

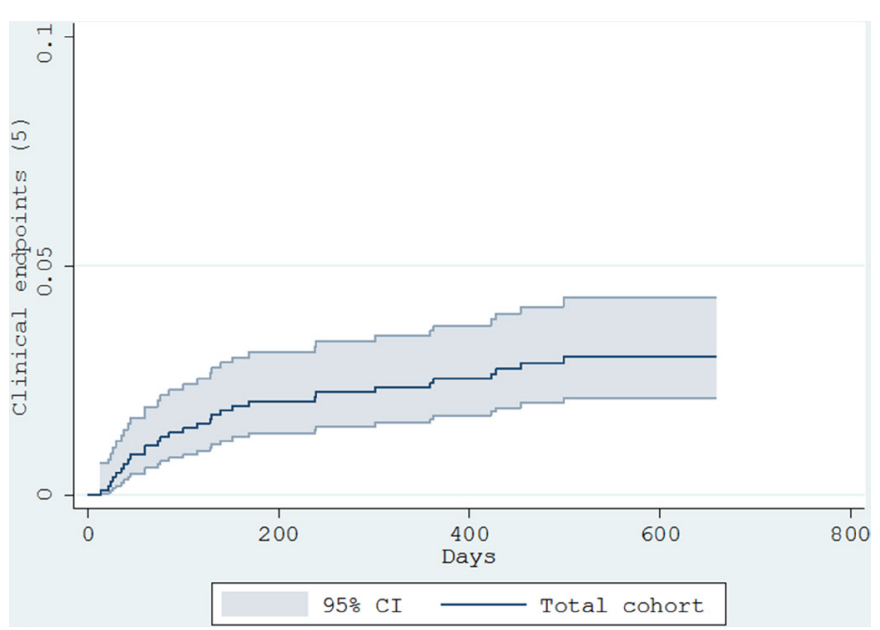

Figure 2 Failure plot with combined endpoints for the total cohort. 
Table 3 HR for exposure variables and endpoints during 1 year of follow-up

\begin{tabular}{|c|c|c|}
\hline Characteristics & $\begin{array}{l}\text { All clinical } \\
\text { events } \\
(n=26)\end{array}$ & $\begin{array}{l}\text { Clinical, cardiac- } \\
\text { related endpoint } \\
(n=19)\end{array}$ \\
\hline \multicolumn{3}{|l|}{ Age (years) } \\
\hline $40+$ & 1 & 1 \\
\hline $50+$ & $1.1(0.3-4.0)$ & $1.0(0.3-3.5)$ \\
\hline $60+$ & $2.8(0.9-8.4)$ & $1.8(0.6-5.6)$ \\
\hline Male & $3.4(1.4-8.1)$ & $4.7(1.6-14.0)$ \\
\hline $\mathrm{BMI}>25 \mathrm{~kg} / \mathrm{m}^{2}$ & $3.0(1.0-7.6)$ & $4.6(1.1-19.7)$ \\
\hline Charlson score $\geq 1$ & $3.2(1.5-6.9)$ & $1.9(0.7-4.8)$ \\
\hline $\begin{array}{l}\text { Smoking }>12 \text { package } \\
\text { years }\end{array}$ & $1.9(0.8-4.3)$ & $2.1(0.8-5.3)$ \\
\hline Alcohol >2 U/week & $0.8(0.4-1.7)$ & $0.9(0.3-2.1)$ \\
\hline \multicolumn{3}{|l|}{ Comorbidity } \\
\hline Coronary artery disease & $3.3(1.5-7.3)$ & $3.8(1.5-9.5)$ \\
\hline $\begin{array}{l}\text { Ischaemic cerebral } \\
\text { disease }\end{array}$ & $1.7(0.4-7.0)$ & $1.1(0.2-8.3)$ \\
\hline $\begin{array}{l}\text { Peripheral arterial } \\
\text { disease }\end{array}$ & $7.4(2.2-24.5)$ & $3.1(0.4-23)$ \\
\hline $\begin{array}{l}\text { Supraventricular } \\
\text { tachycardia }\end{array}$ & $1.5(0.4-6.4)$ & $1.0(0.2-7.6)$ \\
\hline $\begin{array}{l}\text { Combined ischaemic } \\
\text { comorbidity }^{*}\end{array}$ & $4.0(1.9-8.7)$ & $3.6(1.5-8.9)$ \\
\hline Hypertension & $5.2(2.1-12.8)$ & $5.8(1.9-17.5)$ \\
\hline Hypercholesterolaemia & $2.5(1.1-5.9)$ & $6.0(1.7-20.6)$ \\
\hline Diabetes & $5.0(2.2-11.6)$ & $5.2(2.0-13.7)$ \\
\hline Family history of CVD & $1.7(0.7-3.8)$ & $1.6(0.6-4.0)$ \\
\hline Triglycerides $\geq 1 \mathrm{mmol} / \mathrm{L}$ & $1.4(0.5-3.8)$ & $1.0(0.4-2.7)$ \\
\hline Total cholesterol $>5 \mathrm{mmol} / \mathrm{L}$ & $0.5(.2-1.2)$ & $0.4(0.2-1.1)$ \\
\hline LDL >3 mmol/L & $0.5(0.2-1.1)$ & $0.3(0.1-1.0)$ \\
\hline $\mathrm{HDL}<1 \mathrm{mmol} / \mathrm{L}$ & $2.1(0.8-5.5)$ & $3.0(1.1-8.5)$ \\
\hline Statin use & $2.8(1.3-6.2)$ & $4.3(1.8-10.6)$ \\
\hline
\end{tabular}

${ }^{*}$ Combined ischaemic comorbidity consists of coronary artery disease, ischaemic cerebral disease and peripheral vascular disease.

BMI, body mass index; CVD, cardiovascular disease; HDL, high-density lipoprotein; LDL, low-density lipoprotein.

unplanned revascularisation and $0.2 \%$ died. ${ }^{9}$ The second study, a Swedish population-based study that was conducted after implementation of an hsTn assay, ${ }^{10}$ found that 30 days after ED discharge $0.3 \%$ of patients with NSCP had experienced an MI, $0.3 \%$ had undergone coronary revascularisation and $0.2 \%$ had died. These studies reinforce the notion that when clinical events do occur, they tend to do so soon after discharge. ${ }^{10}$

In contrast, other studies have contracted our findings. Jordan et $a l^{19}$ found that patients with NSCP had an increased risk of cardiac events after discharge. Of note, this study did not impose an age limitation, the definition of cardiovascular events included a greater number of diagnoses (such as stroke and periphery arterial disease) and the follow-up time was longer (up to 5.5 years). More importantly, it is unclear where enrolled patients had a normal troponin, and the type of troponin assay would have been markedly different from what is currently used since the inclusion period for this study was from 2002 to 2009. Similarly, Bandstein et al demonstrated a higher event rate for MI when compared with our study. In a cohort of patients aged more than 25 years who presented to the ED with chest pain and had a single hsTn $\mathrm{T}<14$, $1.2 \%(146 / 12033)$ of patients experienced an MI in the year after the index visit. ${ }^{20}$ The difference between this study and our own could be explained by age differences between the cohorts. ${ }^{21}$ Finally, Kelly and Klim ${ }^{22}$ found that patients who presented to the ED with chest pain, but who had a normal ECG and normal troponins, had a mortality rate of $3 \%$ after a median follow-up of 48 months. In addition, during this time frame $0.6 \%$ of the cohort had an MI and $3.1 \%$ underwent revascularisation. Qualifying these findings was again the fact that the cohort was different. Specifically, the cohort was younger, excluded individuals with known CAD and was $55 \%$ male. Furthermore, the study employed an older generation of troponin assay when compared with the hsTn used in our study.

\section{Risk factors for future cardiac-related events among the NSCP with NSCP}

To our knowledge, this is the first study to assess risk factors in NSCP after hsTn implementation. Our study demonstrated that the following variables influence the 1-year risk of a cardiac event: male gender, BMI $>25 \mathrm{~kg} /$ $\mathrm{m}^{2}$, known CAD, other vascular comorbidity, hypertension, hypercholesterolaemia, diabetes mellitus and the use of statins. A total of $73 \%$ of the composite endpoints occurred in males, confirming existing knowledge that male gender is a significant risk factor for CAD. Not surprisingly, most cardiovascular risk stratification tools, such as the Systematic Coronary Risk Evaluation (SCORE), already include gender as a variable in their scoring systems. ${ }^{23}$

Omstedt $e t a l^{9}$ showed that the risk of a future MI, unplanned revascularisation and death in patients with NSCP are associated with age, previous MI, heart failure, hypertension, stroke, hyperlipidaemia, diabetes mellitus and male gender. These risk factors were recognised in our study. Nejatian et als study ${ }^{10}$ showed that admitted patients had a worse prognosis than directly discharged patients. However, admitted patients had a greater number of cardiovascular risk factors, thereby demonstrating that the clinical assessment remains a critical element of chest pain assessment, and that hsTn cannot be considered a stand-alone test when attempting to rule out acute MI.

\section{Strength and limitations}

The strength in our study is that it was a multicentre study with prospective data collection. Moreover, outcome data were obtained from national registration 
systems that are linked to individual civil registration numbers. ${ }^{145}$

However, our study does have some limitations. First, the cohort excluded patients who had a coronary angiography performed during index contact. We chose to exclude these patients as clearly the evaluating physician suspected CAD rather than NSCP. UAP, which was one of the study's cardiac-related endpoints, is a clinician-dependent diagnosis and carries the risk of misclassification of patients that should have a diagnosis of NSCP. Second, 186 patients did not return their consent, the reasons for which were unexplored and hence unclear. Third, we only included patients aged 70 years as it is known that increasing age is an important risk factor for CAD. This could partially explain the difference in findings between our study and other studies, as most other studies did not have an upper age limit. ${ }^{9}{ }^{1020}$ Finally, the main study limitation was the lack of events that occurred during follow-up; unfortunately, this restricted our ability to study risk factors. While a sample size was calculated before beginning the study, the outcome rates from existing literature overestimated the expected outcome rate.

This study demonstrates that patients with NSCP have a good prognosis, with very few patients at risk of death or a clinical, cardiac-related endpoint. The lack of endpoints may help clinicians reassure patients with NSCP, thereby reducing patient anxiety and the risk of readmission. Future research could focus on patients with NSCP using the risk factors identified in this study, or alternatively they could focus on how to reduce the frequency of NSCP patient visits to emergency and cardiology departments.

\section{CONCLUSION}

Our study demonstrates that patients with NSCP have a good prognosis on discharge. Among NSCP patients with cardiac-related endpoints, male gender is a significant risk factor for an adverse outcome among patients with a BMI $>25 \mathrm{~kg} / \mathrm{m}^{2}$, a history of CAD or another vascular comorbidity, hypertension, hypercholesterolaemia, diabetes mellitus and who use statins. Patients who are discharged from the hospital after an initial assessment for acute chest pain, without further investigation, are usually evaluated correctly and can be reassured of a positive prognosis.

\section{Author affiliations \\ ${ }^{1}$ Department of Cardiology, Hospital of Southern Denmark, Aabenraa, Denmark \\ ${ }^{2}$ Department of Cardiology, Odense University Hospital, Odense, Denmark \\ ${ }^{3}$ Department of Emergency Medicine, Odense University Hospital, Odense, Denmark \\ ${ }^{4}$ Department of Internal Medicine, Hospital of Southern Denmark, Sonderborg, Denmark \\ ${ }^{5}$ Department of Medical Research, Odense University Hospital, Svendborg, Denmark ${ }^{6}$ Department of Emergency Medicine, Hospital of Southern Denmark, Aabenraa, Denmark}

Acknowledgements We are indebted to Jens Haastrup (Biochemical Department, Kolding Hospital) for his daily search of troponin values. We want to thank the following hospitals for their collaboration during this study: Emergency Department and Cardiology Department, Hospital of Southern Denmark; Emergency Department and Cardiology Department, Kolding and Vejle Hospital; Emergency Department and Cardiology Department, Odense University Hospital, Odense and Svendborg.

Contributors The steering committee (NI, HM, AL, AD, CBM) designed the study. $\mathrm{Nl}$ and CBM obtained funding. $\mathrm{Nl}$ and $\mathrm{CBM}$ analysed the data. All authors ( $\mathrm{Nl}$, $\mathrm{HM}, \mathrm{AL}, \mathrm{AD}, \mathrm{CBM}, \mathrm{PBS}, \mathrm{TLS}, \mathrm{HMS})$ contributed to the interpretation and revision of the manuscript. All authors (NI, HM, AL, AD, CBM, PBS, TLS, HMS) can take responsibility for the integrity of the data and the accuracy of the data analysis, contributed to the implementation of the study, helped with data interpretation and approved the final report for publication.

Funding This study was funded by the Region of Southern Denmark, Hospital of Southern Denmark, The University of Southern Denmark, and Knud and Edith Eriksens memory foundation.

Competing interests None declared.

Patient consent Obtained.

Ethics approval According to the Regional Scientific Ethical Committees for Southern Denmark, the study did not require ethics clearance (confirmed by email 18 March 2014). The study was registered with The Danish Data Protection Agency (2008-58-0035 number 1086) and approved by the Danish Health Authorities j.nr. 3-3013-573/1 allowing access to discharge diagnosis from the charts.

Provenance and peer review Not commissioned; externally peer reviewed.

Data sharing statement No additional data are available.

Open Access This is an Open Access article distributed in accordance with the Creative Commons Attribution Non Commercial (CC BY-NC 4.0) license, which permits others to distribute, remix, adapt, build upon this work non-commercially, and license their derivative works on different terms, provided the original work is properly cited and the use is non-commercial. See: http://creativecommons.org/ licenses/by-nc/4.0/

(c) Article author(s) (or their employer(s) unless otherwise stated in the text of the article) 2017. All rights reserved. No commercial use is permitted unless otherwise expressly granted.

\section{REFERENCES}

1. Loten C, Isbister G, Jamcotchian M, et al. Adverse outcomes following emergency department discharge of patients with possible acute coronary syndrome. Emerg Med Australas 2009;21:455-64.

2. Nowak R, Mueller C, Giannitsis E, et al. High sensitivity cardiac troponin $\mathrm{T}$ in patients not having an acute coronary syndrome: results from the TRAPID-AMI study. Biomarkers 2017;22:709-14.

3. Body R, Carley S, McDowell G, et al. Rapid exclusion of acute myocardial infarction in patients with undetectable troponin using a high-sensitivity assay. J Am Coll Cardiol 2011;58:1332-9.

4. Carlton EW, Than M, Cullen L, et al. 'Chest pain typicality' in suspected acute coronary syndromes and the impact of clinical experience. Am J Med 2015;128:1109-16.

5. Nichols M, Townsend N, Scarborough P, et al. Cardiovascular disease in Europe 2014: epidemiological update. Eur Heart $J$ 2014;35:2950-9.

6. Cullen L, Greenslade J, Merollini K, et al. Cost and outcomes of assessing patients with chest pain in an Australian emergency department. Med J Aust 2015;202:427-32.

7. Stallone F, Twerenbold R, Wildi K, et al. Prevalence, characteristics and outcome of non-cardiac chest pain and elevated copeptin levels. Heart 2014;100:1708-14.

8. Roll M, Rosenqvist M, Sjöborg B, et al. Unexplained acute chest pain in young adults: disease patterns and medication use 25 years later. Psychosom Med 2015;77:567-74.

9. Omstedt $\AA$, Höijer J, Djärv T, et al. Hypertension predicts major adverse cardiac events after discharge from the emergency department with unspecified chest pain. Eur Heart J Acute Cardiovasc Care 2016;5:441-8.

10. Nejatian A, Omstedt $\AA$, Höijer J, et al. Outcomes in patients with chest pain discharged after evaluation using a high-sensitivity troponin T assay. J Am Coll Cardiol 2017;69:2622-30.

11. Charlson ME, Pompei P, Ales KL, et al. A new method of classifying prognostic comorbidity in longitudinal studies: development and validation. J Chronic Dis 1987;40:373-83.

12. Sundararajan V, Henderson T, Perry C, et al. New ICD-10 version of the charlson comorbidity index predicted in-hospital mortality. J Clin Epidemiol 2004;57:1288-94.

13. Gaist D, Sørensen HT, Hallas J. The Danish prescription registries. Dan Med Bull 1997;44:445-8. 
14. Lynge E, Sandegaard JL, Rebolj M. The Danish national patient register. Scand J Public Health 2011;39:30-3.

15. Pedersen CB. The danish civil registration system. Scand J Public Health 2011;39:22-5.

16. Koerbin G, Tate J, Potter JM, et al. Characterisation of a highly sensitive troponin I assay and its application to a cardio-healthy population. Clin Chem Lab Med 2012;50:871-8.

17. Weber M, Bazzino O, Navarro Estrada JL, et al. Improved diagnostic and prognostic performance of a new high-sensitive troponin T assay in patients with acute coronary syndrome. Am Heart J 2011;162:81-8.

18. Denmarks Statistik. http://www.dst.dk/da/Statistik

19. Jordan KP, Timmis A, Croft P, et al. Prognosis of undiagnosed chest pain: linked electronic health record cohort study. BMJ 2017;357:j1194.
20. Bandstein N, Ljung R, Johansson M, et al. Undetectable high-sensitivity cardiac troponin T level in the emergency department and risk of myocardial infarction. J Am Coll Cardiol 2014;63:2569-78

21. Wang $\mathrm{H}$, Watson $\mathrm{K}$, Robinson $\mathrm{RD}$, et al. Chest pain risk scores can reduce emergent cardiac imaging test needs with low major adverse cardiac events occurrence in an emergency department observation unit. Crit Pathw Cardiol 2016;15:145-51.

22. Kelly AM, Klim S. Long term prognostic value of a negative work-up for acute coronary disease in emergency department chest pain patients without known coronary artery disease: a cohort study. Heart Lung Circ 2017;26.

23. Conroy RM, Pyörälä K, Fitzgerald AP, et al. Estimation of ten-year risk of fatal cardiovascular disease in Europe: the SCORE project. Eur Heart J 2003;24:987-1003. 